\title{
CAK NUN DAN ESAI SASTRAWINYA DALAM PERSPEKTIF KRIMINOLOGI
}

\author{
Anas Ahmadi \\ anasahmadi@unesa.ac.id \\ Jurusan Bahasa dan Sastra Indonesia, FBS, Universitas Negeri Surabaya
}

\begin{abstract}
Criminology studies are related to crime studies. Criminology studies attract many academics because these studies are dynamic and can be included in various study areas, one of them is the study of criminology that is included in the study of literature. As a form of creation of the author, literature also raises things related to criminology. In this research, criminology is presented in the Indonesian literary essay. In this case, Indonesian literature is limited to Emha Ainun Najib's work in the form of literary essays. This qualitative-interpretive research study uses data sources from Slilit Sang Kiai (2013); Arus Bawah (2015); and Gelandangan di Kampung Sendiri (2015). The theory used in this research is criminology theory. Based on the analysis, it was concluded that Cak Nun as a cultural figure presented crimes in his literary essay, which is as follows. First, based on an analysis of the criminological context, the forms of crime in Emha Ainun Najib's work include, among others (1) crime of environmental destruction; (2) questionnaire manipulation crime; (3) murder crime; (4) crime of prostitution; and (5) white-collar crimes. Secondly, the tendency of crime to emerge in the work of Emha Ainun Najid through her three works, which is more towards the crime of the government to the people. Second, the tendency of crime that is raised in the work of Emha Ainun Najib through his three works are more directed at government crime against the people.
\end{abstract}

Keywords: criminology, Indonesian literature, essay-literature

Abstrak: Studi tentang kriminologi berkait dengan studi kejahatan. Studi kriminologi banyak menarik perhatian akademisi sebab studi ini dinamis (Siegel, 2018:xvi) dan bisa masuk dalam berbagai wilayah kajian. Salah satunya adalah studi kriminologi yang masuk dalam studi sastra. Sebagai bentuk kreasi sang pengaran, sastra juga memunculkan hal yang berkait dengan kriminologi. Dalam penelitian ini dipaparkan kriminologi dalam esai sastrawi (sastra) Indonesia. Dalam hal ini, sastra Indonesia dibatasi pada karya Emha Ainun Najib yang berbentuk esai-sastrawi. Penelitian berpendekatan kualitatif-interpretatif ini menggunakan sumber data Slilit Sang Kiai (2013); Arus Bawah (2015); dan Gelandangan di Kampung Sendiri (2015). Teori yang digunakan dalam penelitian ini adalah teori kriminologi. Berdasarkan analisis diperoleh simpulan bahwa Cak Nun sebagai sosok budayawan menampilkan kejahatan-kejahatan dalam esai sastrawinya, yakni sebagai berikut. Pertama, berdasarkan analisis konteks kriminologis, bentuk kejahatan dalam karya Emha 
Ainun Najib, antara lain (1) kejahatan perusakan lingkungan; (2) kejahatan manipulasi angket; (3) kejahatan pembunuhan; (4) kejahatan prostitusi; dan (5) kejahatan kerah putih. Kedua, kecenderungan kejahatan yang dimunculkan dalam karya Emha Ainun Najib melalui ketiga karyanya, yakni lebih mengarah pada kejahatan pemerintah kepada rakyat.

Kata kunci: kriminologi, sastra Indonesia, esai-sastrawi

\section{PENDAHULUAN}

Kriminologi merupakan kajian dalam wilayah hukum dan kejahatan (Weisburd, 2015:134), baik hukum dan kejahatan konteks realitas maupun konteks virtual (Urbanik \& Harggerty, 2018; Jaishankar, 2011; Atkinson \& Rodgers). Dalam pandangan Shoham \& Hoffman (2012), kriminologi menjadi perhatian para filsuf, psikolog, sosiolog, antropolog, dan sastrawan. Berkait dengan konteks kesastraan, kriminologi bisa digunakan sebagai alat bantu untuk membedah masalah kriminologi yang terdapat dalam sastra tersebut. Dalam kriminologi, salah satu aspek yang sering dijadikan sebagai bahan kajian adalah kejahatan yang dilakukan oleh orang dalam konteks individual ataupun dalam konteks komunal (korporat). Dalam pandangan Bohm (1982:584) korporat sebagai kaum borjuasi lebih banyak menyumbangkan kejahatan daripada kaum proletarian.

Kejahatan dalam masyarakat modern muncul di kalangan kaum borjuis-salah satu yang paling mendunia-- dikenal dengan kejahatan kerah putih (white-collar crime). Merujuk penelitian yang dilakukan oleh Grabosky (2009:129), peningkatan kejahatan kerah putih (white-collar crime) saat ini tidak lepas dari efek globalisasi. Para pemimpin politik melakukan kerja sama dan deal politis dengan kejahatan/pelaku kejahatan (Scheingold, 1998:589) sehingga memunculkan kerja sama yang ilegal. Karena itulah, saat ini marak kejahatan transnasional, money laundry, dan peretasan ilegal. Sejalan dengan hal itu, Stiglitz (2006:7) menggarisbawahi bahwa globalisasi memantik kejahatan. Kelompok yang sangat dirugikan adalah kelompok kelas bawah dan yang diuntungkan adalah kelompok kelas atas. Dalam konteks psikologi, Fromm (1973) menandaskan bahwa kejahatan manusia modern muncul karena jiwa instinktif. Selain itu, jika merujuk pada pandangan Zimbardo (2007), manusia modern lebih mudah melakukan kriminologi sebab memiliki kedekatan dengan lingkungan yang mengarah pada kriminologis. Dengan demikian, kejahatan takkan pernah bisa berakhir selama instinksi itu masih ada.

Sastra sebagai salah satu medium estetis juga memunculkan kriminologi di dalamnya. Munculnya kriminologi dalam sastra dianggap sebagai bumbu estetis, tetapi ada pula yang memunculkan kriminologi sebagai bentuk perlawanan. Simaklah W.S. Rendra dengan puisipuisinya yang terkumpul dalam Potret Pembangunan dalam Puisi (1996). Rendra dengan garang mengecam, mencaci, bahkan menghujat pemerintahan yang korup, jahat, dan ambigu. Kriminologi dalam sastra tak seekstrim pemunculan kriminologi dalam berita di media. Karena itu, pada masa pascaorba sempat muncul dan ramai istilah ketika jurnalisme bungkam, sastrawan berbicara. Sastra menyuarakan hati nurani yang terbelenggu, kriminalitas yang tak diperbincangkan oleh media, dan hal-hal yang dianggap tabu oleh masyarakat.

Sastra mengusung hal yang berkait dengan kriminologi secara eksplisit maupun implisit. Harapannya, melalui medium sastra, masyarakat bisa melek kriminologi yang selama ini mendarah daging dan mengurat nadi. Media tak berani berkicau semaunya. Fakta menunjukkan, Majalah Tempo dibredel sebab memberitakan kecurangan pemerintah dalam 
hal pembelian kapal bekas. Mulanya, pada persidangan awal di Pengadilan Negeri, Tempo tidak dibredel. Selanjutnya, pihak penggugat mengajukan Tempo ke Pengadilan Tinggi, hasilnya, Tempo tidak dibredel. Namun, ketika di Mahkamah Agung, Tempo diputuskan untuk dibredel (Dhakidae, 2003) oleh pemerintah. Leak (2014) menunjukkan bahwa korupsi yang dilakukan oleh manusia sebenarnya menjiplak dari instink binatang. Simaklah kecoa. Ia adalah binatang yang mampu bertahan selama sembilan hari meskipun kepalanya terpenggal. Begitu pula dengan para koruptor, meskipun tidak menduduki jabatan/berkuasa, mereka masih berdaya untuk mengendalikan kehidupannya dengan sentosa. Dalam konteks Frommian, manusia sebenarnya bukan belajar nikrofilia, tetapi belajar biofilia. Menjadi manusia yang arif dengan belajar kearifan dari semesta (Ahmadi, 2018) yang merupakan sumber kehidupan semesta.

Di Indonesia, penelitian tentang sastra konteks kriminologi bukanlah hal yang baru. Pertama, Budiono yang meneliti novel karya S. Mara Gd perspektif Kriminologi. Budiono mengungkapkan adanya kejahatan bentuk pemerasan dan pembunuhan novel Dendam Seorang Istri (Satwikobudionowordpress). Kedua, Utafiya (2011) melakukan penelitian sastra konteks kriminologi. Jika Budiono menggunakan sastra genre novel, Utafiya menggunakan sastra genre cerbung. Ia meneliti cerbung Kenya Kebak Wewadi. Temuan penelitiannya, salah satunya adalah aspek kriminalitas yang meliputi pembunuhan serta penyuapan yang muncul dalam cerbung.

Berdasarkan penelitian terdahulu yang relevan tersebut belum pernah ada yang meneliti kriminologi dalam karya-karya Cak Nun (Emha Ainun Nadjib) yang termaktub dalam kumpulan esai sastrawinya, yakni Slilit Sang Kiai (2013); Arus Bawah (2015); dan Gelandangan di Kampung sendiri (2015). Esai tersebut bukanlah tulisan terkini Cak Nun, tetapi tulisan lama yang direpro. Slilit Sang Kiai (repro 1991; Gelandangan di Kampung sendiri (repro, 1995); dan Arus Bawah (repro, 1994). Dalam penelitian ini, peneliti berusaha memetakan kejahatan (crime mapping) dimunculkan dalam karya-karya Cak Nun. Namun, pemetaan ini tidak sepenuhnya mengikuti model pemetaan kriminologi sesungguhnya, pemetaan spasial (spatial mapping) ataupun pemetaan temporal (temporal mapping) (Piquero \& Weisburg, 2010:16). Pemetaan ini lebih bersifat fleksibel. Harapannya, bisa diperoleh hasil analisis yang tidak kaku dan kering sebab kajian ini adalah kajian kesastraan melalui perspektif kriminologi, bukan kajian kriminologi murni.

Penelitian terdahulu yang berkait dengan karya Emha Ainun Nadjib, sepanjang pengetahuan peneliti terpapar sebagai berikut. Pertama, Suwargono (2016) yang meneliti Slilit Sang Kiai dari perspektif sufisme. Berdasarkan analisis, Suwargono menunjukkan bahwa Slilit Sang Kiai memunculkan tingkatan sufisme mulai dari eksperimentasi, kesadaran sosial, dan kesadaran religius. Kedua, Pratiwi (2013) yang meneliti Arus Bawah melalui tindak pembungkaman terhadap punakawan yang dilakukan oleh Pak Kades. Hasil penelitian menunjukkan bahwa ada beberapa aspek yang berhubungan dengan tindak pembungkaman, yaitu penyebab tindak pembungkaman, bentuk-bentuk tindak pembungkaman, dampak tindak pembungkaman, dan usaha perlawanan terhadap tindak pembungkaman.

Kriminologi ialah ilmu yang mempelajari kejahatan dan perilaku kriminal. Secara khusus, bidang kriminologi berkonsentrasi pada bentuk-bentuk kriminal, sebab-sebab kejahatan, definisi kriminalitas, dan reaksi masyarakat terhadap aktivitas kriminal; bidangbidang pengkajian terkait bisa meliputi kenakalan (delinquen) remaja dan victimology (Hagan, 2013:2-3). Kriminologi merupakan ilmu yang masih belum kokoh layaknya filsafat, psikologi, antropologi, dan sosiologi. Kriminologi masih bersifat terbuka, umum, 
dan partikular (Walklite, 2007). Karena itu, tidak salah jika Tierney (2006:26) menyebut kriminologi sebagai ilmu yang bersifat parasit sebab menempel pada ilmu hukum, psikologi, psikiatri, dan sosiologi/antropologi. Dengan demikian, kriminologi sebagai ilmu tak mampu berdiri sendiri laiknya ilmu yang lain.

Dalam pandangan Urgen \& Inderbitzin (2010), kriminologi tidak hanya masuk dalam wilayah hukum. Namun, publik juga bisa mempelajarinya, menganalis, dan mengkritisinya. Karena itu, ada studi tentang proffesional criminology dan public criminology. Adapun dalam konteks perempuan, mereka bisa berperan aktif dalam studi kriminologi feminis (Moore, 2007:48), yang di dalamnya berbicara tentang eksistensi perempuan dalam ranah kriminologi. Dalam pandangan psikolog, kriminologi salah satunya adalah membahas penyebab munculnya kriminalitas dalam diri seseorang. Kecenderungannya, kriminalitas disebabkan oleh ketidaksadaran individual (individual unconsciousness), fantasi (fantasy), represi (repression), hasrat (desire), bizarre (Gaad \& Jefferson, 2007:4-5). Kajian kriminologi memang mencantolkan diri pada ilmu-ilmu lain, tetapi yang tampak mencolok muncul dalam kriminologi adalah ilmu hukum, ilmu psikologi, dan ilmu sosiologi. Kriminologi tidak lepas dari hukum sebab kriminalitas tidak pernah jauh dari hukum. Tatkala seorang psikopat, nikrofil, koprofil, ataupun fetish melakukan kejahatan, harus ditinjau perspektif psyche-nya. Karena itu, kriminologi butuh bantuan psikologi. Ketika banyak orang berlomba korupsi ataupun anak muda melakukan kejahatan jalanan, harus ditinjau konteks sosialnya. Bagaimana kehidupan mereka dimasyarakat (pengaruh-dipengaruhi) sehingga melakukan tindak kejahatan.

Studi kriminologi sebagai sebuah metode hampir sama dengan studi sosiologi, tetapi Crow \& Semmens (2007) memberikan batasan bahwa studi kriminologi memiliki keunikan. Studi kriminologi melibatkan studi yang berkait dengan hal ilegal, isu sensitif, narkoba, ataupun masalah traumatis. Dengan demikian, studi kriminologi lebih mengarah pada aspek sosial yang berkait dengan hukum, pengadilan, kebenaran, etika, dan moralitas. Dalam perkembangan kekinian, kriminologi masuk dalam studi postmodernisme (Schwartz \& Friedrichs, 1994). Namun, studi kriminologi dalam bingkai postmodernisme belum begitu marak.

Hagan (2013:iii--vii) membagi jenis kriminalitas secara general, yakni (1) kejahatan kerah putih [kejahatan korporat, KKN [korupsi, kolusi, dan nepotisme], cuci uang]), (2) kejahatan properti (kejahatan properti sesekali [klipto, vandal]; (3) kejahatan properti konvensional [pembobolan, pembakaran]; kejahatan properti profesional [skema Ponzi]), (4) kejahatan politik (ideologi, terorisme, genoside); (5) kejahatan terorganisasi (cuci uang, narkoba [kejahatan antarnegara]), (6) kejahatan ketertiban publik (prostitusi, nuds), dan (7) kejahatan komputer/cyber (virus, predator [uang, perempuan, anak]). Berkait dengan jenis kriminologi, Haines \& Sutton (2000) menambahkan kriminologi konteks agama/religi, sedangkan Wood (2014) menambahkan jenis kriminologi lesbian, gay, bisexual, transgender, and queer (LGBTQ).

Studi kriminologi dalam ranah sastra meliputi tga wilayah, yakni (1) studi kriminologi yang berkait dengan proses kreatif sang pengarang dalam melahirkan karya sastra; (2) studi kriminologi yang berkait dengan bentuk-bentuk kejahatan yang terdapat dalam teks kesastraan; dan (3) studi kriminologi yang berkait dengan pembaca karya sastra. Dalam penelitian ini, yang digunakan adalah bentuk yang kedua, yakni studi kriminologi dalam teks karya sastra.

Tujuan penelitian ini, yakni memaparkan secara eskploratif deskriptif-naratif bentuk kejahatan yang terdapat dalam tiga esai sastrawi karya Emha Ainun Najib. Adapun manfaat 
14 | Bahasa dan Seni: Jurnal Bahasa, Sastra, Seni, dan Pengajarannya

Volume 47, Nomor 1, Februari 2019

penelitian, secara keilmuan, diharapkan hasil penelitian dapat memberikan kontribusi dalam khasanah kritik sastra perspektif kriminologi.

\section{METODE}

Penelitian ini menggunakan pendekatan kualitatif-interpretatif sebab data yang digunakan berupa paparan deskriptif yang diinterpretasikan oleh peneliti. Interpretasi tersebut, merujuk pada pandangan Creswell (2009), dikonstruk dengan menggunakan interpretasi secara induktif yang dibangun dari aspek khusus menuju ke umum. Dalam perspektif kriminologi, studi ini menggunakan metode krimonologi-kualitatif (Carrabine, et al. 2009:30). Metode kriminologi-kualitatif dalam konteks penelitian lebih memfokuskan pada pendeskripsian dan penarasian data. Dalam pandangan Jones (2017:9), metode kualitatif dalam kriminologi yang menggunakan deskripsi adalah sebuah pengupayaan untuk menemukan kepemahaman (verstehen).

Sumber data yang digunakan dalam penelitian ini berupa tiga karya Emha Ainun Nadjib yang dikategorikan sebagai esai sastrawi, antara lain (1) Slilit Sang Kiai (2013); (2) Arus Bawah (2015); dan (3) Gelandangan di Kampung sendiri (2015). Data yang digunakan berupa kata, frasa, dialog, paragraf yang relevan dengan konteks kriminologi. Teknik analisis data menggunakan model heuristis, yakni (1) pembacaan teks untuk memahami makna yang terdapat di struktur permukaan (surface structure) dan (2) pembongkaran makna yang terdapat di struktur dalam (deep structure). Melalui kedua penahapan teknik analisis data tersebut diharapkan hasil analisis data bisa dipertanggungjawabkan kadar keilmiahannya, baik secara metodologis maupun empiris.

\section{DISKUSI DAN HASIL PEMBAHASAN}

\section{Kriminologi dalam Slilit sang Kiai}

Sebagai sebuah karya imajinatif, sastra tidak lepas dari interseksi antara fiksi dan realitas yang terdapat dalam masyarakat. Jika dalam realita memunculkan kriminologi dengan berbagai bentuk, demikian juga dalam sastra yang merupakan miniatur dari realitas. Karena itu, dalam sastra tidak sepenuhnya otonom, tetapi masih memiliki kaitan dengan realitas yang ada dalam masyarakat.

\section{Kejahatan Perusakan Lingkungan}

Dalam Slilit sang Kiai (2013), Cak Nun (sebutan akrab Emha Ainun Nadjib) memunculkan kejahatan yang terpapar sebagai berikut. "Slilit sang Kiai" mengisahkan kejahatan pejabat negara yang menghabiskan kayu glondongan di hutan Kalimantan. Kejahatan menguras habis sumber daya alam Indonesia tanpa tedeng aling-aling. Si pejabat (biasanya diplesetkan penjahat) tidak pernah takut menggerogoti sumber daya alam sebab ia berada di bawah kibaran bendera kekuasaan. Gambaran tersebut tampak pada kutipan berikut.

“...slilit pernah memusingkan seorang kiai di alam kuburnya, bahkan mengalami kemungkinan suksesnya masuk surga. Ceritanya, dia mendadak dipanggil Tuhan, sebelum para santrinya siap untuk itu. Murid-murid setia itu, sesudah menguburkan sang kiai, lantas nglembur ngaji berhari-hari -agar diperkenankan bertemu dengan ruh beliau barang satu dua jenak. Dan Allah 
yang Maha Memungkinkan segala kejaian akhirnya menunjukkan tanda kebenaran-Nya dalam mimpi para santri. Ruh kiai itu bertemu dengan mereka. Terjadilah wawancara singkat, perihal nasib sang kiai "di sana". "Baik-baik, Nak. Dosa-dosaku umumnya diampuni. Amalku diterima Cuma satu hal yang membuatku masgul. Kalian ingat waktu aku memimpin kenduri di rumah Pak Kusen? Sehabis makan bareng, hadirin berebut menyalamiku sehingga tak sempat aku mengurus slilit di gigiku. Ketika pulang, di tengah jalan, barulah bisa kulakukan sesuatu. Karena lupa enggak bawa tusuk slilit, maka aku ambil potongan kayu kecil dari pagar orang. Kini, alangkah sedihnya aku: aku tak sempat minta maaf kepada yang empunya perihal tindakan mencuri itu? Apakah Allah bakal mengampuniku?" (Nadjib, 2015:18)

Para santri turut berduka. Kemudian membayangkan alangkah lebih malangnya nasib sang kiai bila slilit di giginya itu, serta tusuk yang dicurinya itu, sebesar kayu gelondongan kayu raksasa di hutan Kalimantan (Nadjib, 2015:18)

Gambaran tentang slilit sang kiai dalam kutipan tersebut sebenarnya merupakan ironi yang dilakukan oleh pejabat terhadap hutan. Jika seorang kiai merasa bersalah gara-gara mengambil slilit, para pejabat seharusnya harus merasa bersalah ketika mereka menebang kayu di hutan secara gelondongan. Kejahatan kecil bagi orang religius dianggap sebagai sebuah kejahatan yang besar sehingga mengakibatkan mereka tidak bisa masuk surga. Namun, para pejabat yang memiliki Hak Pengusahaan Hutan (HPH) melakukan penebangan hutan dengan kedok HPH tersebut sama sekali tidak memiliki rasa bersalah terkait dengan perusakan lingkungan yang dilakukan dengan cara sengaja dan terang-terangan. Para pejabat adalah sosok yang taktersentuh (untouchable) ketika melakukan kejahatan dalam masalah perusakan lingkungan hutan. Ketika mereka menebang hutan secara sembarangan, tidak ada yang berani menangkapnya. Berkait dengan konteks kriminologi, kejahatan penebangan hutan secara ilegal dilakukan oleh kaum borjuasi yang memiliki kuasa dan legalitas untuk menebang hutan. Kaum borjuasai dalam konteks ini adalah pejabat dan juga korporat. Merekalah yang memiliki kekuasaan penuh dalam hal pengelolaan hutan.

Kejahatan terhadap lingkungan (green criminology) di era globalisasi ini memang semakin merajalela dan meningkat drastis. Adapun salah satu penyebabnya adalah penguasa dan korporat. Hal ini sejalan dengan pandangan Lynch, et al (2015) yang menunjukkan bahwa koporat turut mendukung terjadinya kerusakan lingkungan di berbagai negara. Selain itu, munculnya kriminologi lingkungan juga disebabkan rasa alienasi manusia modern yang semakin lama semakin menguat dalam diri manusia modern. Semakin modern seseorang, semakin teralienasi dari lingkungan

\section{Kejahatan Manipulasi Angket}

Kejahatan yang banyak muncul dalam konteks penelitian salah satu di antaranya adalah angket. Pemanipulasian angket dilakukan demi diperolehnya hasil penelitian yang diinginkan oleh kelompok peneliti tertentu. Karena itu, kejahatan pemanipulasian angket melahirkan fabrikasi dan falsifikasi penelitian. Ketika penelitian bersifat fabrikatif dan falsifikatif, hasilnya tidak lagi bisa dipertanggungjawabkan secara ontologis, aksiologis, dan epistemologis.

"Angket" mengisahkan kejahatan yang berkait dengan angket. Dalam "Angket" dikisahkan bahwa di suatu kota, ada tiga ratus responden laki-laki yang beristri. Mereka ditanya soal "bersantap di meja makan rumah" dan "jajan juga di luar rumah". Hasilnya, dua ratus responden menjawab, ya. Dengan demikian, 2 dari 3 laki-laki yang sudah beristri di kota tersebut hidung belang. Gambaran tersebut tampak pada kutipan berikut. 
16 | Bahasa dan Seni: Jurnal Bahasa, Sastra, Seni, dan Pengajarannya

Volume 47, Nomor 1, Februari 2019

Pretensi penelitian itu sendiri yang sebenarnya bisa bagus dan luhur, tapi terperosok menjadi bombastis dan curang ketika secara keseluruhan sesungguhnya tidak diberangkatkan dari kemauan moral yang sungguh-sungguh untuk menciptakan antitesis terhadap gejala imoralitas (Nadjib, 2013:64)

Selama ini, angket memang digunakan sebagai penanda bahwa khalayak/responden/informan memberikan pilihan/argumentasi/deskripsi mereka terhadap sesuatu. Dipercaya atau tidak, banyak angket yang isinya benar, tetapi proses pengisiannya yang tidak benar. Karena itu, tidak salah jika muncul ungkapan hasil angketnya tidak salah, tetapi proses/cara/metode menuju hasil angket tersebut yang salah. Mereka, para pemain angket memainkan angket untuk korporasi, kepentingan media, kepentingan lembaga. Karena itulah, fabrikasi, falsifikasi dilakukan demi yang namanya kebenaran metodologis. Namun, kebenaran metodologis yang nisbi sehingga memberikan penyesatan berita dan memunculkan kebohongan publik.

"Matahari memata-matai Hari" memunculkan kejahatan pejabat yang sering diskusi/seminar. Mereka memang mendiskusikan masalah rakyat miskin, bagaimana agar masyarakat bisa maju, dan pembangunan yang merata. Jujur, diskusi/seminar itu bagus sebab dalam konteks yang idealis-filosofis kegiatan tersebut (diskusi/seminar) ingin memecahkan suatu masalah yang problematis/pelik/urgen. Karena itu, kegiatan yang disebut diskusi/seminar tersebut perlu dirancang jauh hari dan kegiatannya juga memakan waktu yang lama. Berhari-hari. Namun, dalam konteks idealis-pragmatis. Diskusi/seminar hanya jadi dagelan semata. Mereka di sana tidak memperbincangkan rakyat besok apa makan? Tetapi mereka mendiskusikan besok makan apa? Selang waktu lima tahun (sekitar tahun 2010) di salah satu stasiun televisi swasta menayangkan sosok pejabat negara yang selesai kunjungan di luar negeri. Tatkala ia ditanya isi kunjungan/hasil kunjungan, si pejabat bilang dengan entengnya, "tanyakan pada panitia, saya bukan panitianya." Luar biasa. Bahkan, yang lebih luar biasa lagi. Ada pejabat dari daerah Jawa wilayah timur yang kunjungan ke luar negeri. Ceritanya begitu, tetapi mereka malah ngendon di Jakarta, heppy-heppy. Makan di resto dan tidur di hotel bintang lima. Setelah itu, pulang ke Jawa wilayah timur. Hasil laporannya, mereka sudah melakukan kunjungan ke luar negeri.

\section{Kejahatan Pembunuhan}

"Glangsing, Rileks, dan Ringan" menuturkan pembunuhan yang menggunakan glangsing. Konon, pembunuhan bermediakan glangsing marak pada zaman sebelum reformasi dan sesudah orde lama. Orang yang tidak sesuai dengan hasrat pemerintah, mereka harus di-glangsing-kan. Inilah kejahatan modern tentang pembunuhan. Jika pada zaman dahulu ada genoside, di Indonesia ada glangsingside. Pembunuhan yang tidak usah pake repot sebab si mayat dimasukkan dalam glangsing yang harganya 2000-an. Kejahatan glangsing ini tak pandang bulu -dan memang tak semua bulu boleh dipandang - siapa yang melawan, glangsing!

\section{Kejahatan Prostitusi}

Kejahatan prostutisi adalah kejahatan yang paling purba di dunia dan menurut Prakash (2013) prostitusi juga merupakan profesi yang paling tua di dunia. "Goyang Kiai Sekati" mengisahkan gelombang prostitusi yang sudah menggilai dan menggulai dunia. Gelombang itu tidak hanya di Barat, tetapi di Indonesia juga. Cak Nun juga menyindir kalangan 
agamawan yang menidak tentang hal ini, tetapi sebenarnya mengiya. Prostitusi memang sebuah kejahatan purba sekaligus surga. Apakah disebut kejahatan ataukah tidak, tetapi dalam kaitannya dengan kriminologi, prostitusi merupakan kejahatan atau tidak. Jika ditilik, memang tidak ada kejahatan dalam konteks antarpemain. Namun, Hagan (2013:619) memberikan parameter bahwa yang menjadi unsur kriminalitas adalah metode pengumpulan, penjualan, dan pencarian konsumen untuk membayar -yang kesemuanya cenderung ilegal. Pada masa Abad Pertengahan -pemunculan The Dark of Middle Age-kejahatan jenis ini disebut dengan 'kejahatan yang dibutuhkan'. Prostitusi merupakan profesi rendah, tetapi ada prostutisi kalangan tinggi. Karena itu, di Yunani dikenal dengan hetaeare; di Romawi dikenal dengan lupanaria; di India dikenal dengan devadadis; dan di Jepang dikenal dengan Geisha. Esai "17.000 Kartu Nama" mengisahkan hal senada dengan "Goyang Kiai Sekati". Perempuan penjaja seks konon banyak yang sudah memiliki rumah lebih dari satu, punya mobil, dan mereka punya 17.000 kartu nama. Apa yang membuat mereka ajeg menjalani pekerjaan itu. Masih prostitusi, "Ibu-ibu dari Surga" juga mengisahkan potret buram prostitusi. Ibu yang layaknya sosok menyurga, tetapi meneraka. Mereka terkadang menjual putrinya.

Penelitian prostitusi yang dilakukan Malarek -wartawan asal Ukrania-sangatlah menarik untuk cermati. Ia meyimpulkan bahwa gelombang prostitusi terbagi menjadi empat. Gelombang awal muncl tahun 70-an, gelombang dua muncul tahun 80 -an, gelombang tiga muncul tahun 90-an, dan gelombang empat muncul saat saat ini. Ia memaparkan bahwa banyaknya prostitusi -kaitannya dengan PSK - disebabkan oleh keterpaksaan dan penipuan oleh pihak luar atau dalam (Malarek, 2003:24-25).

Edisi prostitusi dulu sampai sekarang dalam pandangan Baudrillard (2004:186-187) dirangkum dalam ranah konsumsi masyarakat tradisional dan modern. Prostitusi merupakan konsumsi yang tak pernah habis dan tak lekang oleh waktu. Selalu saja cepat habis seperti jual kacang.

\section{Kriminologi dalam Gelandangan di Kampung Sendiri}

\section{Kejahatan Kerah Putih}

Dalam Gelandangan di Kampung Sendiri terpapar kejahatan sebagai berikut. Esai "Lingsem" mengisahkan kejahatan pejabat negara, kejahatan yang konon dikenal dengan kejahatan kerah putih (white-collar crime). Mereka para pejabat membuat regulasi yang dalam perspektif rakyat - merugikan rakyat. Hal ini digambarkan dari dipugarnya Gedung Senisono, Yogya. Gedung ini dipugar dengan dalih mengurangi kadar aktivitas aktivis yang menentang orde baru. Gambaran tersebut tampak pada kutipan berikut.

...kasus Senioso, Yogya yang pembongkarannya telah disyahkan oleh SK dan ber-DIP pula: batalnya pembongkaran akan identik dengan pelanggaran konstitusi. Para seniman budayawan yang menuntut pembatalan pembongkaran akan berposisi sebagai pelawan konstitusi (Nadjib, 2015:6)

Gambaran tersebut menunjukkan bahwa pemerintah mempunyai kuasa segalanya dalam hal membuka atau menutup sesuatu. Apalagi, dalam hal ini, gedung seni Senioso tersebut diduga sebagai ajang para aktivis yang menentang Orde Baru. Selain itu, adanya regulasi pembangunan waduk di Jawa Tengah. Pemerintah memang memberikan ganti rugi kepada masyarakat. Namun, masyarakat merasa bahwa ganti rugi yang diberikan tidak sebanding. Karena itu, yang diinginkan oleh masyarakat bukanlah 'ganti rugi', tetapi 'ganti tambah'. 
Masyarakat hanya bisa mengeluh sebab tak mampu melakukan apa-apa. Jika mereka rakyat-melawan, menolak, mereka akan di-glangsing-kan. Dalam pandangan Apel \& Paternoster (2009), kejahatan kerah putih merupakan kejahatan yang besar. Kejahatan ini tidak hanya melibatkan pemerintah, tetapi juga melibatkan korporat dalam melakukan tindakan ilegal. Karena itu, kejahatan yang dilakukan oleh pejabat dan korporat yang dilindungi atau bersembunyi di balik aturan memang sulit di lawan oleh rakyat. Rakyat

Esai “Sunyi Kopra di Pulau Kei” menggambarkan tegangan poros atas dan poros bawah. Artinya, pemerintah banyak menyerap pundi-pundi hasil bumi dari daerah-daerah, tetapi tidak memberikan kontribusi yang balance bagi masyarakat di daerah. Pemerintah pusat bergelimang harta, sedangkan masyarakatdi daerah bergelimang kemiskinan. Ironis memang, tetapi faktanya demikian. Kisah dari Freeport salah satunya dari tragedi poros atasporos bawah. Masyarakat di sana masih jauh dari peradaban modernis, tetapi hasil kekayaan dari tempat tersebut dikerukhabis-habisan. Karena itu, demo/protes/dan kekerasan tidak terelakkan. Kecemburuan sosial sangat kuat. Warga pribumi, masih saja seperti itu dari dulu sampai sekarang, kelaparan, buta huruf, ringkih, dan belum menikmati hasil kerukan wilayahnya sendiri secara optimal.

"Buruh 1", "Buruh 2", dan Buruh 3" mengisahkan kejahatan para pemilik perusahaan terhadap anak buahnya. Mereka kalangan borjuasi dengan mudahnya memecat karyawan yang tidak sejalan dengan pemikiran majikan. Bos-bos perusahaan akan memecat karyawankaryawan yang suka mogok kerja -tuntutannya adalah kenaikan gaji, malas kerja, dan suka provokasi. Logikanya, majikan ingin memberikan gaji sekecil-kecilnya, sedangkan karyawan ingin mendapatkan gaji yang sebesar-besarnya. Namun, berterima ataupun tidak tetap saja karyawan merupakan kendaraan yang harus dipelihara dengan baik. Jika kendaraan tidak dirawat dengan baik, mogok pun pasti terjadi. Begitulah sunnatullahnya perusahaan. Majikan dan karyawan haruslah memiliki sinergisitas tinggi. Namun, selama ini, kecenderungan majikan memeras keringat para karyawan dan karyawan hanya mendapatkan secuil kebahagian. Tidak sebegitu lama, sekitar tahun 2013, ada sebuah pabrik panci yang memperkerjakan 20-an karyawan. Mereka tidak digaji selama tiga bulan, mereka diminta kerja keras, makan yang diberikan adalah makanan yang tak layak.

Esai "Balada Farida dan Mbah Jiwo" mengisahkan kejahatan pembunuhan yang dilakukan Mbah Jiwo (nenek) kepada Farida -masih anak-anak dan cucunya Mbah Jiwo. Ia membunuh dengan cara yang sadistis. Si Faridah dicincang menjadi 79 bagian, disimpan, dan dijadikan lauk rawon. Kejahatan jenis ini adalah kejahatan jenis purba. Kejahatan menghilangkan nyawa manusia.

\section{Kriminologi dalam Arus Bawah}

Arus Bawah (2015) -merujuk pada pengantar penerbit dari buku ini-- merupakan novelesai yang pada mulanya terbit bersambung di Harian Berita Buana (28 Januari-31 Maret 1991). Novel esai ini menarik untuk dibaca lagi meskipun situasi Indonesia mungkin sudah banyak yang berubah dibandingkan saat novel ini ditulis. Saat itu Indonesia berada pada masa Orde baru yang punya kehati-hatian luar biasa pada setiap suara rakyat.

\section{Kejahatan Kerah Putih}

Tidak jauh beda dengan Slilit sang Kiai ataupun Gelandangan di Kampung Sendiri, Arus Bawah juga memunculkan kejahatan-kejahatan. Dalam Arus Bawah dimunculkan cerita per 
segmen. Karena itu, dalam analisis ini juga diambil segmen yang kuat memunculkan kejahatan. Segmen "Budaya Politik Pra-Wayang" mengisahkan warga Desa Karang Kedempel yang harus satu suara. Tunggal. Jika menyuarakan sesuatu. Tafsir harus tunggal, tidak boleh jamak. Gambaran ini menyiratkan masa kepemimpinan ORBA yang harus tunggal -meskipun tidak pernah dimunculkan secara eksplisit harus tunggal. Masih terngiang di telinga saya, dulu para pelamar kerja di slot PNS ketika diwawancara konon harus menyelipkan kata 'saya penganut pohon beringin'. Jika tidak demikian, jangan harap bisa tembus PNS. Sungguh luar biasa apa yang disebut dengan kejahatan tunggal. Jika ada yang berbeda, hancurkan, bubarkan, bila perlu gilas ataupun glangsing.

Segmen "Monopoli dan Distribusi Wahyu 1.500 Dukun" mengisahkan bahwa raja memiliki kekuatan adikodrati yang tak tergoyahkan. Ia adalah tangan Tuhan. Semuanya harus menuruti apa yang dikatakan sang raja sebab apa yang dikatan sang raja adalah kebenaran. Gambaran tersebut tampak pada kutipan berikut.

Salah satu bias dari teori Lesan Pembakar adalah anggapan bahwa Raja sebagai wadah pemusatan kekuasaan kosmis pastilah merupakan manusia yang paling sakti. Kekuasaan politik yang digenggamnya adalah manifestasi dari kesaktiannya (Nadjib, 2015:137).

Gambaran tersebut menyiratkan bahwa kejahatan sosok pemerintah yang otoriterian. Tangan besi. Apapun yang dikatakan harus dilakukan oleh rakyatnya. Tak peduli benar ataupun salah. Padahal, raja/pemimpin adalah pelayan rakyat. Merekalah yang membantu meladeni, melayani, mendengar, dan menyenangkan rakyat bukan sebaliknya. Melalui judulnya, kita pun diajak tahu apa itu monopoli. Ternyata sang raja melakukan monopoli besar-besaran terhadap segala sumber kekayaan alam yang ada. Itulah kejahatan. Penguasaan dengan cara monopoli ataupun kartel.

\section{SIMPULAN}

Berdasarkan analisis diperoleh simpulan bahwa Cak Nun sebagai sosok budayawan memunculkan kejahatan-kejahatan dalam karya kreatifnya, tiga di antaranya, yakni Slilit Sang Kiai (2013); Arus Bawah (2015); dan Gelandangan di Kampung sendiri (2015). Pertama, berdasarkan analisis konteks kriminologis, bentuk kejahatan dalam karya Emha Ainun Najib, antara lain (1) kejahatan perusakan lingkungan; (2) kejahatan manipulasi angket; (3) kejahatan pembunuhan; (4) kejahatan prostitusi; dan (5) kejahatan kerah putih. Kedua, kecenderungan kejahatan yang dimunculkan dalam karya Emha Ainun Najid melalui ketiga karyanya, yakni lebih mengarah pada kejahatan pemerintah kepada rakyat. Sosok rakyat banyak disakiti oleh pemerintah. Rakyat adalah sosok yang ditindas, sedangkan pemerintah adalah sang penindas. Kejahatan yang lain, misal pembunuhan, prostitusi, ataupun pencurian sekadar kembangan untuk mengangkat tema utama, yakni kejahatan pemerintah.

\section{DAFTAR RUJUKAN}

Ahmadi, A. 2018. Korupsifilia: Fiksi dan Fakta. Duta Masyarakat, 5 Oktober.

Apel, R. \& Paternoster, R. 2009. Understanding "Criminogenic" Corporate Culture: What White-Collar Crime Researchers Can Learn from Studies of the Adolescent EmploymentCrime Relationship. In S.S. Simpson, D. Weisburd (eds.), The Criminology of WhiteCollar Crime. London: Springer. 
20 | Bahasa dan Seni: Jurnal Bahasa, Sastra, Seni, dan Pengajarannya Volume 47, Nomor 1, Februari 2019

Atkinson, R. \& Rodgers, T. 2015. Pleasure Zones and Murder Boxes: Online Pornography and Violent Video Games as Cultural Zones of Exception, The British Journal of Criminology, 56 (6): 1291-1307. https://doi.org/10.1093/bjc/azv113.

Baudrillard, J.P. 2004. Masyarakat Konsumsi. Diterjemahkan Wahyunto. Yogyakarta: Kreasi Wacana.

Bohm, R.M. 1982. Radical Criminology. Criminology, 19 (4):565-589.

Budiono, S. 2015. Novel Dendam Seorang Istri Karya S Mara Gd dalam Kajian Kriminologi. Dalam Satriobudionowordpress. Diunduh tanggal 22 April 2018.

Carrabine, et al. 2009. Criminology: A Sociological Introduction. London: Routledge.

Creswell, J. W. 2009. Research Design, Qualitative, Quantitative, and Mixing Approaches. London: Sage.

Dhakidae, D. 2003. Cendekiawan dan Kekuasaan. Jakarta: Gramedia.

Haines, F. \& Sutton, S. 2000. Criminology as Religion? The British Journal of Criminology, 40 (1): 146-162, https://doi.org/10.1093/bjc/40.1.146

Hagan, Frank E. 2013. Kriminologi: Teori, Metode, dan Perilaku Kriminal. Terjemahan A.K. Anwar. Jakarta: Kencana.

Gaad, D. \& Jefferson, T. 2007. Psychosocial Criminology. London: Sage.

Grabosky, P. 2009. White-Colar Crimes and the Fear of Crime. In S. Simpson \& David P. (eds). The Criminology of White-Collar Crime. Israel: Springer.

Fromm, E. 1973. The Anatomy of Destructiveness. New York: Holt, Rinehart, \& Winston.

Jaishankar, K. 2011. Introduction Expanding Cyber Criminology with an Avant-Garde Anthology. In K. Jaishankar (ed.). Cyber Criminology: Exploring Internet Crimes and Criminal Behavior. London: Taylor \& Francis Group.

Jones, S. 2017. Criminology. Sixth Edition. London: Oxford.

Leak, Sosiawan. 2015. "Instink Korupsi”. Artikel dalam Jawa Pos tanggal 26 April.

Lynch, et al. 2015. Environmental justice: a criminological perspective. Environ. Res. Lett. 10, https://doi:10.1088/1748-9326/10/8/085008.

Malarek, V. 2003. Natasha: Menyibak perdagangan Seks Dunia. Penerjemah Zia Anshor. Yogyakarta: Serambi.

Moore, D. 2007. Feminist Criminology: Gain, Loss and Backlash. Sociology Compass, 2 (1) 48-61.

Nadjib, E. A. 2013. Slilit sang Kiai. Yogyakarta: Mizan.

Nadjib, E. A. 2015a. Arus Bawah. Bentang: Yogyakarta.

Nadjib, E. A. 2015b. Gelandangan di Kampung Sendiri. Yogyakarta: Mizan.

Piquero, Alex A. \& Wesburd, D. 2010. Handbook of Quantitative Criminology. London: Springer.

Pratiwi, E.D. 2013. Tindak pembungkaman dalam novel Gerakan Punakawan Atawa Arus Bawah karya Emha Ainun Nadjib. Skripsi. Jakarta: UI.

Prakash, H. 2013. Prostitution and Its Impact on Society-A Criminological Perspective. International Research Journal of Social Sciences, 2(3), 31-39.

Rendra, W.S. 1996. Potret Pembangunan dalam Puisi. Jakarta: Pustaka Jaya.

Reka, Utafiya. 2011. Aspek Kriminalitas dalam Cerbung Salindri Kenya Kebak Wewadi Karya Pakne Puri. Skripsi tidak diterbitkan. Surakarta: UNS.

Sceingold, S.A. 1998. Constructing the New Political Criminology: Power, Authority, and the Post-Liberal State. Law and Social Inquiry, 23 (4): 857-895. 
Stiglitz, Joseph E. 2006. Making Globalization Work. Penerjemah Edrijani A. Yogyakarta: Mizan.

Schwartz, M.D. \& Friedrichs, D.O. 1994. Postmodern Thought and Criminological Discontent: New Metaphors for Understanding Violence. Criminology, 32 (2): 212-246.

Soham, S.G. \& Hoffman, J. 2012. Sociology of Crime. Harrow \& Heston Publishers: Albany. Siegel, L.J. 2018. Criminology: the Core. Seventh Edition. Cengage: Boston.

Suwargono, W.A. 2016. Sufistic Reflection of Emha Ainun Nadjib In Slilit Sang Kiai. Tesis. Purwokerto: IAIN Purwokerto.

Tierney, John. 2006. Criminology: Theory and Context. London: Longman.

Urgen, C. \& Inderbitzin, M. 2011. Public Criminologies. Criminology and Public Policy, 9 (4): 725-749.

Urbanik, M. \& Haggerty, K.D. 2018. '\#It's Dangerous': The Online World of Drug Dealers, Rappers and the Street Code. The British Journal of Criminology, 58 (6): 1343-1360, https://doi.org/10.1093/bjc/azx083

Walklite, S. 200. Understanding Criminology. New York: McGrill.

Weisburd, D. 2015. The Law of Crime Concentration and the Criminology of Place. Criminology, 53 (2): 133-157. https://doi.org/10.1111/1745-9125.12070.

Wood, J.B. 2014. "Queering Criminology": Overview of the State of the Field. In D. Peterson and V. R. Panfil (eds.), Handbook of LGBT Communities, Crime, and Justice. New York: Springer.

Zimbardo, P.G. 2007. Lucifer Effect. New York: Random House. 